\title{
La crisis de la deuda, el euro y la construcción política europea: reflexiones desde la economía
}

\author{
The Debt Crisis, the Euro and European Political \\ Integration: Reflections from the Economy
}

\author{
Antón CosTAS \\ Universitat de Barcelona \\ acostas@ub.edu \\ Santiago Lago PeÑas \\ Universidade de Vigo \\ slagop@uvigo.es
}

\section{Resumen}

En este trabajo, se plantea la cuestión hacia qué dirección se dirigirá la crisis de la deuda soberana, evaluando, si existen circunstancias que lo encaminen hacia la integración o no, de la Unión Europea. Alemania como economía consolidada, aunque con una visión equivocada de la crisis, puede escoger actuar como líder cooperante o hegemónico para tratar de ir más allá de la lógica actual del euro, diseñando un esquema donde el BCE tome más importancia en la creación de objetivos comunes, que den un nuevo impulso al proyecto de unión política. Por otro lado, se realizará una comparativa con la experiencia de Estados Unidos en materia de unidad fiscal, para concluir en que es necesario fortalecer la idea de unidad política Europa. Sin embargo, este será un largo tránsito y de final desconocido.

Palabras clave: unión política europea, crisis deuda soberana, liderazgo cooperativo, currency board, unidad fiscal.

\begin{abstract}
This paper examines which direction the sovereign debt crisis will take, considering whether or not there are circumstances that will lead to the integration of the European Union. Germany, as a consolidated economy, although with a misguided vision of the crisis, can choose to act as a cooperative leader or a hegemonic leader, in order to go beyond the current logic of the euro and design a scheme where the ECB has greater weight in the creation of common objectives, which will give new
\end{abstract}


impetus to the project of political union. On the other hand, the paper will also compare the experience of the United States in the area of fiscal union, to conclude that it is necessary to strengthen the idea of political unity in Europe. However, this will be a long journey with an unforeseeable ending.

Keywords: European political union, sovereign debt crisis, cooperative leadership, currency board, fiscal union.

\section{1. ¿Una crisis integradora o desintegradora?}

La pregunta central a la que nos enfrentamos en estos momentos en la Unión Europea (UE) es si la actual crisis de la deuda soberana será una crisis integradora o desintegradora. ¿Dará lugar a un avance hacia una arquitectura más acabada de la UE y del euro como verdadera moneda común de una unión política, o, por el contrario, acabará siendo una crisis desintegradora de la propia eurozona como hoy la conocemos? Responder a esta cuestión no es fácil, porque no existen experiencias anteriores similares que se puedan utilizar como referencia. Necesariamente, debemos movernos en un plano más exploratorio y tentativo.

Para este cometido vale la pena pertrecharse del bagaje analítico que nos proporciona el enfoque "salida, voz y lealtad" desarrollado por el economista y politólogo Albert O. Hirschman, fallecido cuando redactamos estas líneas. En un ensayo publicado en los años ochenta, titulado "Tres usos de la economía política en el análisis de la integración europea", Hirschman ${ }^{1}$ aplicó su enfoque para tratar de discernir en qué circunstancias una crisis en el proceso de construcción europea podría derivar en un avance en la integración o en el sentido contrario. Es decir, en una "crisis desintegradora" que lleva a los Estados nacionales a marchar solos, o en una "crisis integradora" que conduce a los miembros a buscar alguna acción concertada para avanzar en el proceso de integración. La observación de la historia de la integración europea, permite a Hirschman formular, a modo de hipótesis, la siguiente pregunta: “¿Podremos concluir que las crisis repentinas, dotadas de una causa claramente identificable, serán desintegradoras, mientras que las dificultades de desarrollo más lento, mal entendidas serán integradoras?"

Pensamos que esta es una conjetura útil para aplicar a la coyuntura presente, por dos motivos. Primero, porque por inesperada e imprevista, la crisis de deuda soberana de la eurozona se puede calificar de "repentina". Y segundo, porque desde Alemania y los países de influencia germánica se ha creído saber, a nuestro juicio equivocadamente, que había una causa claramente identificable: la prodigalidad fiscal de los países sobreendeudados.

\footnotetext{
${ }^{1}$ A. O. Hirschman, "Tres usos de la economía política en el análisis de la integración europea", en De la Economía a la Política y más allá, México, FCE, 1984.
} 
La idea de que fueron los excesos presupuestarios de los gobiernos la causa de la crisis de deuda soberana se ha convertido en un dogma de fe, y ha conformado lo que podríamos llamar la visión germánica de las causas de la crisis. Esta visión tiene mucho que ver con la resistencia alemana a avanzar hacia un mayor gobierno económico de la Unión Económica y Monetaria (UEM) y a permitir al Banco Central Europeo (BCE) ejercer las funciones propias de un banco central convencional. Por lo tanto, es importante dilucidar en qué medida fueron los excesos presupuestarios previos a la crisis financiera de 2008 la causa de la crisis de deuda o la causa estuvo en otro lado.

Con la excepción quizá del caso griego, en el que sí ha existido una conducta de exceso de gasto y ocultación del déficit público, en los demás países los problemas de la deuda soberana no responden a la visión alemana. Irlanda y España acreditaban superávits presupuestarios y bajos niveles de deuda pública hasta 2008. El déficit público y el aumento de su deuda pública no fueron la causa sino la consecuencia de, por un lado, de los efectos de la crisis financiera y económica y, por otro, de la necesidad de salir al rescate de las instituciones bancarias privadas.

Por tanto, a la hora de acertar en la estrategia de salida de la crisis de la deuda soberana y en la construcción de la nueva arquitectura de la UEM, es fundamental reconocer que ha sido el sector privado financiero y no el público el talón de Aquiles de la eurozona. Los fundadores del euro creyeron que los desequilibrios para la sostenibilidad del euro procederían del sector público. No fueron conscientes de que podrían originarse también en el sector privado. Si tenemos en cuenta esta enseñanza, surgen de inmediato dos conclusiones importantes. Primera, no es suficiente con el diseño de nuevos instrumentos de intervención para el caso de situaciones de emergencia soberana, sino que la reforma del sistema financiero europeo debe figurar también en lugar destacado en la nueva arquitectura de gobierno de la UEM. Segunda, el no tener en cuenta este error de comprensión de los hechos puede tener consecuencias importantes sobre la dinámica de integración europea.

Mientras persista esta visión de que la crisis de deuda soberana tiene una explicación claramente identificable en la prodigalidad fiscal de los gobiernos, entonces la crisis que vivimos puede acabar siendo desintegradora. Como ha señalado De Grauwe, la obstinación alemana en imponer un mecanismo de resolución de la misma según el cual la carga recae exclusivamente sobre los acreedores es pura y simplemente la negación de la existencia de la eurozona ${ }^{2}$. Si, por el contrario, las causas de la crisis de la deuda se perciben en toda su complejidad, no como un problema causado por el fallo del sector público de los países sobreendeudados sino como un fallo del sector privado financiero del conjunto de la UEM y de otros desequilibrios macroeconómicos distintos a los presupuestarios, entonces la crisis puede acabar siendo integradora.

\footnotetext{
${ }^{2}$ P. De Grauwe, "La crisis de la deuda soberana y el futuro del euro", en Claves de la Economía Internacional 3, 2011, pp. 16-23.
} 


\section{Alemania y la eurozona: ¿liderazgo cooperativo o hegemonía?}

Alemania ha emergido en medio de esta coyuntura como la potencia central de la eurozona, tanto en el sentido geográfico, como económico y político. Se puede decir que Alemania manda. Su poder no se fundamenta solo en su reconocida fortaleza económica y su capacidad exportadora, facilitada por la estabilidad cambiaria de la eurozona. Se basa en que es el socio que tiene la mejor calidad crediticia y en que su economía se encuentra en mejores condiciones para utilizar su demanda interna a modo de locomotora para el crecimiento de la eurozona, con el consiguiente beneficio para los países endeudados.

No obstante, Alemania ha sido remisa a desempeñar esa función tractora hasta ahora. Por el contrario, su equivocada visión de las causas de la crisis de deuda lleva a responsabilizar a los países endeudados de sus propias desdichas y les impone drásticos e intempestivos programas de austeridad que, combinados con la imposibilidad de utilizar la devaluación nominal del tipo de cambio, no harán sino empeorar su situación: se obstaculiza el crecimiento y se dificulta la tarea de afrontar los compromisos de la deuda. Además Alemania ha actuado hasta ahora con deslealtad, propagando comentarios inoportunos o ambiguos, que hacen aún más inconfortable la situación de los países en dificultades y mantiene sobre ellos la espada de Damocles de la quiebra y el rescate, haciéndoles rehenes de un juego que parece ir dirigido a mantener la hegemonía alemana dentro de la eurozona.

Todo esto está generando preocupación y un cierto resentimiento en otros miembros de la UE. Son muchos los que se preguntan cuál es la visión de Alemania sobre el futuro de la UE y de qué forma va ejercer su nuevo poder. De cómo lo utilice dependerá la prosperidad de la eurozona e incluso la propia existencia futura del euro. Hasta ahora su conducta parece orientarse a hacer lo necesario para mantener el euro a flote, pero minimizando la exposición de los contribuyentes alemanes a las políticas de apoyo a la eurozona. Pero permanece la duda acerca de cómo se comportará a medio y largo plazo. ¿Cómo usará Alemania ese nuevo poder? ¿Lo hará mediante un liderazgo conciliador y responsable, ejercido sin retorcer el brazo o zarandear a los otros países, o lo hará como ejercicio de hegemonía, es decir, usando la ley del más fuerte? Si falla en elegir el rol adecuado para gobernar los actuales desequilibrios financieros y económicos de la eurozona se puede encontrar que cuando despierte de su error haya perdido la eurozona.

Para responder a estas preguntas, vamos a ir de la mano, esta vez, de Charles P. Kindleberger. En dos ensayos titulados "Jerarquía frente a cooperación" y "La comunidad europea: ¿jerarquía o federación?", incluidos en su libro El orden económico internacional, Kindleberger ${ }^{3}$ analiza si la hegemonía es necesaria para la

\footnotetext{
${ }^{3}$ Ch. P. Kindlerberger, "La Comunidad Europea: ¿Jerarquía o Federación?”, en El orden económico internacional, Barcelona, Crítica, 1992.
} 
estabilidad de una unión o si puede ser proporcionada por un liderazgo responsable y cooperativo entre los estados-nación que forman parte del sistema. Kindleberger aporta dos posibles salidas. La primera se basa en la idea de que lo que determina la actuación de los estados es la búsqueda del propio interés y que es improbable que ningún país - al menos a corto plazo - tenga el incentivo a actuar como líder solidario, asumiendo el esfuerzo de estabilizar la economía de la unión con los costes que eso comporta. De ahí que, bajo esta hipótesis, su comportamiento tienda a ser hegemónico. La segunda proporciona una respuesta más optimista, tal vez romántica, pero en cualquier caso es una posible salida institucional. De acuerdo con ella, los regímenes internacionales y las uniones económicas que han surgido en la posguerra pueden producir suficiente inercia para generar un liderazgo cooperativo que persiga el interés general del grupo.

Depende, por tanto, de cómo Alemania entienda cual es su propio interés a corto y a largo plazo. En un primer momento, apoyándose en ese nuevo orden transitorio basado en la ley del más sano crediticiamente, el país germano parece haber optado por la hegemonía. Un ejercicio de prevalencia en el que domina la búsqueda de sus propios intereses a corto plazo y que deja poco espacio para el liderazgo colectivo y para convicciones morales, responsabilidad histórica, o conceptos como el deber y la obligación del líder. Una de las consecuencias más visibles de esta forma de ejercer su nuevo poder ha sido el debilitamiento de las instituciones comunitarias, la retirada de apoyo a avances supranacionales y el fortalecimiento de su papel como principal actor de las relaciones con Rusia, Asia, Latinoamérica o los Estados Unidos, en perjuicio de la voz y la acción de las instituciones colectivas comunitarias.

Sin embargo, no hay que descartar que, poco a poco, y de acuerdo con la segunda hipótesis de Kindleberger, Alemania acabe orientando el uso de su poder a través de un ejercicio de liderazgo responsable y cooperativo. Y ello por dos razones. Primera, por una mejor evaluación de sus propios intereses a largo plazo en relación con la eurozona. Segundo, por la propia inercia a la cooperación que potencialmente pueden introducir las instituciones comunitarias y de la eurozona, en particular, el BCE. El papel de esta institución puede ser esencial. Vale la pena explorarlo.

\section{3. ¿Puede el euro ir más allá de su actual lógica de una "currency board"?}

Hay que reconocer que a lo largo de 2012 se han ido dando pasos incrementales que pueden finalmente llevar hacia un diseño del euro como moneda de una unión política. El agravamiento de la recesión y del paro en la UE, las dificultades de liquidez de la banca europea, la creciente fragmentación monetaria y financiera de la UEM y la elevación de las primas de riesgo de España e Italia a niveles que hacían presagiar una ruptura del euro han llevado al BCE, bajo la presidencia del italiano Mario Draghi, a tomar una serie de decisiones que han significado un paso adelante muy importante en la configuración del BCE como un verdadero banco central. Por 
un lado, ha comenzado a desarrollar funciones de prestamista de última instancia del sistema bancario europeo al suministrar liquidez sin restricciones. Por otro, a partir de la transcendental intervención de Mario Draghi a finales de julio de 2012 en Londres, señalando que el BCE haría todo lo necesario para salvar el euro, el BCE ha diseñado un esquema que le permitirá desarrollar algunas funciones de prestamista de los gobiernos, en la medida en que podrá intervenir "sin límites" en los mercados secundarios de deuda. Si bien es cierto que, de momento, esa posibilidad está limitada por la necesidad de que haya una petición del país y el acuerdo unánime de los miembros del eurogrupo.

Estas nuevas funciones del BCE como prestamista de última instancia surgen de la lógica institucional y han conseguido vencer la renuencia alemana, al menos del Bundesbank, el banco central alemán, a ir más allá de la lógica económica que hasta ahora había marcado el funcionamiento del euro. Una lógica que era más propia de un mercado común de países que comparten una moneda que de moneda de una unión política. De ahí que los padres fundadores del euro no hubiesen previsto dotar al BCE de las competencias o instrumentos de intervención característicos de un banco central convencional.

Como uno de nosotros ha señalado en un reciente trabajo ${ }^{4}$, la lógica que subyace al diseño del euro es la de un mecanismo de estabilidad cambiaria para el funcionamiento de un mercado interior único. En esto no es muy diferente de lo que sucedía con la serpiente monetaria de los años setenta y el sistema monetario europeo de los años ochenta. De acuerdo con esa lógica, la autoridad monetaria del euro estaba más próxima a lo que en la historia financiera se conoce como una "currency board" que a un banco central. De ahí que el euro no haya contemplado la existencia de mecanismos propios de una moneda de una unión política, como la unión fiscal que permita mecanismos de "comunitarización" de la deuda o un Banco Central con capacidad para actuar de prestamista de última instancia, para suministrar liquidez en situaciones como las que estamos viviendo.

Coherente con esa lógica de mercado común, el euro se ha basado hasta ahora más en mecanismos de coordinación que operan a través de los mercados que de mecanismos de solidaridad propios de una unión política. La crisis de 2008 parece, sin embargo, haber proporcionado un nuevo espacio para las políticas frente a la anterior hegemonía del mercado ${ }^{5}$. Se ha abierto una ventana de oportunidad para cambiar la lógica de la "unión cambiaria" propia del diseño inicial del euro por una lógica de moneda de una unión política. Al actuar como lo ha hecho el BCE parece haberse comportado como sugiere la segunda hipótesis de Kindleberger, en el sentido de que

\footnotetext{
${ }^{4}$ A. Costas, "El euro, ¿moneda única o «currency board»?, en Revista de Economía de Galicia 21 (núm. extraordinario), 2012, pp. 1-24.

${ }^{5}$ X. C. Arias y A. Costas, La Torre de la arrogancia. Políticas y mercados después de la tormenta, Barcelona, Ariel, 2011.
} 
las uniones económicas pueden generar un liderazgo cooperativo que vaya más allá del interés particular de sus miembros para perseguir el interés general del grupo.

Las espadas están aún en alto y es difícil discernir si la crisis llevará a una dinámica integradora europea o desintegradora. El miedo a las consecuencias económicas, sociales y políticas de una ruptura del euro es hasta ahora la única fuerza que parece sostener la moneda única. Pero el temor no puede ser el único pegamento del euro. Se necesita algún otro objetivo común que de nuevo impulso al proyecto de unión política.

\section{El espejo norteamericano}

A medida que la crisis avanzaba, se ha visto con claridad creciente que la eurozona necesita algo más que disciplina procedente de Alemania. De ahí que el sentido común y la lógica institucional hayan impuesto la necesidad de diseñar una arquitectura más permanente para hacer frente tanto a la situación actual, como ante situaciones futuras. Los más fervientes partidarios de la unidad política de Europa han aprovechado para señalar que la supervivencia del euro como moneda única europea necesita ser contrabalanceada por la existencia de una gobernanza que cuenten con el soporte de un gran presupuesto federal y un Tesoro capaz de emitir deuda propia (eurobonos). Esa gobernanza económica, al estilo de la del gobierno federal de Estados Unidos, permitiría desarrollar dos tipos de funciones. Por un lado, políticas contracíclicas que ayuden a la economía europea a salir de la recesión, actuando de consumidor de última instancia. Por otro, actuar como prestamista de última instancia de gobiernos solventes pero con problemas de liquidez. Sin embargo, parece ilusorio pensar que en el corto y medio plazo esta propuesta de máximos sea una solución viable.

Sin duda, para ir más allá de la limitativa lógica de mercado común que da hoy sostén al euro, es necesario avanzar hacia la unión política. Ese tránsito no será fácil dada la pérdida de impulso europeísta que ha dominada la acción política en las últimas décadas. Para caminar en esa dirección algunos expertos han sugerido una estrategia de "pequeños pasos" en distintas direcciones ${ }^{6}$. En particular, convertir en permanentes los actuales mecanismos de apoyo financiero a los países del euro, optar por la emisión conjunta de eurobonos y caminar hacia una coordinación de las políticas económicas nacionales.

A la búsqueda de caminos de salida para la actual situación de endeudamiento soberano y debilidad institucional que vive la eurozona, muchos han encontrado inspiración para sus propuestas en los Estados Unidos de Norteamérica. EE.UU. es quizá la más exitosa unión monetaria que ha existido en la historia. Para unos ese éxito demuestra que una unión monetaria no puede sobrevivir sin una unión fiscal. Otros

\footnotetext{
${ }^{6}$ P. De Grauwe, op. cit.
} 
señalan el hecho de que al existir un prestamista de último recurso tanto para los Estados como la banca comercial ha permitido tanto a los Estados como al Gobierno Federal afrontar mejor la crisis. Otros, en fin, han argumentado que la existencia de un profundo y líquido mercado de bonos públicos respaldado por la Reserva Federal está permitiendo a los EE.UU. seguir endeudándose a tasas de interés nominal próximas a cero, algo que le permite a la vez desendeudarse y crecer.

La experiencia norteamericana de unidad fiscal está siendo también una fuente de inspiración para el caso europeo. Así, se ha propuesto un "pacto de redención" de deuda soberana europea al estilo del modelo de asunción de deudas de guerra que llevó a cabo el gobierno federal de EE.UU. en 1790. Este plan, diseñado por Alexander Hamilton, el primer Secretario del Tesoro, provocó inicialmente una profunda división entre los Estados, al negarse Virginia y otros Estados del sur, que habían redimido su deuda, a financiar el rescate de los estados sobreendeudados. Pero mediante concesiones de diverso tipo a los estados opositores (entre ellas la decisión de localizar la capital federal, Washington, en las fronteras del Estado de Virginia) Hamilton consiguió que retiraran su oposición a la comunitarización de la deuda y logró la unión fiscal.

Sin embargo, la existencia de una verdadera política fiscal y monetaria común tardaría aun más de un siglo. Hasta la Gran Depresión de los años treinta la presencia del gobierno federal en la economía norteamericana fue minúscula. Su presupuesto fue generalmente inferior al 2\% del PIB estadounidense (frente al $25 \%$ en la actualidad), una situación bastante parecida al presupuesto actual de la UE. Por otro lado, fue frecuente a lo largo de este período la adopción de leyes para limitar el crecimiento del déficit y de la deuda pública, tal como hoy estamos viendo en la UE. A la vez, la política monetaria y financiera de EE.UU. sufrió frecuentes altibajos $\mathrm{y}$, prácticamente, no hubo un banco central digno de tal nombre hasta la segunda década del siglo xx.

Esta historia tortuosa hacia la unidad fiscal y monetaria ha llevado a The Economist a recordar que lo que hoy vemos como una historia de éxito fue, de hecho, un proceso largo, doloroso y complicado. Aunque es indudable que la unión monetaria y fiscal contribuyó al crecimiento económico de EE.UU, el semanario The Economist, apoyándose en investigaciones recientes, recuerda que sus instituciones fiscales y monetarias fueron tan rudimentarias durante tanto tiempo que por fuerza contribuyeron escasamente a la construcción de la nación americana. En este sentido, fue más importante la movilidad interna del trabajo y del capital que permitía que cuando en un Estado había un elevado desempleo la gente pudiese moverse libremente buscando mejores oportunidades en otros. De ahí que la lección fundamental que extrae de la experiencia de los Estados Unidos es que lo que mantuvo la construcción de la nación y la unidad económica tuvo menos que ver con las instituciones fiscales y monetarias que con el deseo de la gente por lograr una cohesión política más intensa. 


\section{Un camino largo, difícil y de final incierto}

El corolario para la UE de la experiencia norteamericana de unión fiscal y monetaria es que, si se quiere hacer una verdadera moneda común, es necesario fortalecer el deseo de la gente de construir una verdadera unidad política europea. En un artículo reciente, Pascal Petit ${ }^{7}$ ha sugerido que ese nuevo impulso puede surgir de la necesidad de responder al malestar de los jóvenes europeos ("malaise of the youth") y de las clases medias y trabajadoras que han estado experimentando caídas de salarios y disminución de la seguridad social a lo largo de las últimas décadas, caídas exacerbadas por las políticas de austeridad. Eso permite pensar en la posibilidad de un New Deal europeo, gestionado por una autoridad central responsable de políticas activas para los jóvenes, al estilo de cómo la UE ha hecho hasta ahora con los fondos estructurales para desarrollar infraestructuras. Esta política, unida a otros programas orientados a grupos sociales en situaciones de riesgo de exclusión en todos los países miembros, ayudaría a reducir la creciente oposición de movimientos populistas y a aliviar las presiones anti-Europa que proyectan sobre los gobiernos. Probablemente esta es una buena formula para llevar a cabo aquellas "realizaciones concretas" capaces de crear "solidaridades de hecho" entre los ciudadanos de los países miembros de la UE que recomendaba la Declaración Schuman de 1950 para construir la unión política europea.

A lo largo de 2012, el miedo a las consecuencias de la ruptura del euro y la inercia institucional implícita en sus instituciones han permitido al BCE romper su lógica inicial de "currency board" para transformarse en un verdadero banco central. El avance hacia la unión bancaria europea es también otro paso importante adoptado bajo la presión de las circunstancias. Pero la definitiva consolidación del euro como moneda común necesitará de la unión política que, a su vez, requiere un nuevo impulso político. Un nuevo impulso que probablemente no puede venir sólo de un mayor grado de cooperación intergubernamental, sino que requerirá de la creación de una institución política europea de representación directa que pueda representar el interés general europeo, más allá de los intereses particulares de sus miembros. Pero, en todo caso, este tránsito será largo y con final incierto.

\footnotetext{
${ }^{7}$ P. Petit, "Building faith in a common currency: can the eurozone get beyond the Common Market logic?" en Cambridge Journal of Economics 36, 2012, pp. 271-281.
} 